\title{
Substituição do Milho pela Farinha de Mandioca de Varredura em Dietas de Cabras em Lactação: Fermentação Ruminal e Concentrações de Uréia Plasmática e no Leite ${ }^{1}$
}

\section{Gisele Fernanda Mouro ${ }^{3}$, Antonio Ferriani Branco 2,5, Francisco Assis Fonseca de Macedo 2, 5, Kátia Cilene Guimarães ${ }^{3}$, Claudete Regina Alcalde ${ }^{2}$, Rosemeri Aparecida Ferreira ${ }^{4}$, Paulo Emílio Fernandes Prohmann ${ }^{3}$}

\begin{abstract}
RESUMO - O objetivo deste trabalho foi avaliar o efeito da substituição do milho pela farinha de mandioca de varredura, em dietas de cabras Saanen em lactação, sobre a degradabilidade potencial, efetiva e efetiva corrigida das rações, bem como sobre o pH ruminal e as concentrações de amônia ruminal, uréia plasmática e uréia no leite em cabras em lactação. Foram utilizadas quatro cabras há 100 dias em lactação. O delineamento utilizado foi o quadrado latino 4 x4, em que os tratamentos consistiram em níveis de $0,33,67$ e $100 \%$ de substituição do milho pela farinha de mandiocade varredura. A degradabilidade das rações experimentais foi determinada em bovinos pela técnica in situ. Apesar de a degradabilidade potencial das dietas experimentais ter tido pequena variação para MS, PB e amido, a degradabilidade efetiva e a degradabilidade efetiva corrigida da MS, da PB e do amido aumentaram com a substituição do milho pela farinha de varredura de mandioca. Os tratamentos não influenciaram o $\mathrm{pH}$ ruminal, bem como as concentrações de $\mathrm{NH}_{3}$-ruminal, uréia plasmática e uréia do leite. Houve correlação positiva $(\mathrm{P}<0,05 ; \mathrm{r}=0,9288)$ entre as concentrações de uréia plasmática e a uréia do leite, permitindo estimativas da uréia plasmática a partir da equação $\mathrm{UP}(\mathrm{mg} / \mathrm{dL})=0,7672 \mathrm{UL}(\mathrm{mg} / \mathrm{dL})+7,4894\left(\mathrm{R}^{2}=0,8628\right)$. Conclui-se que a farinha de mandioca de varredura pode substituir totalmente o milho e ser utilizada em rações de cabras em lactação, em nível de até $30 \%$ da ingestão de MS, sem prejuízos para parâmetros ruminais e metabolismo do nitrogênio.
\end{abstract}

Palavras-chave: cabras leiteiras, degradabilidade, mandioca, rúmen, uréia

\section{Replacement of Corn by Cassava By-Product Meal in the Lactating Goat Diets: Effects on Diet Degradability, Ruminal Fermentation and Plasma and Milk Urea Concentrations}

\begin{abstract}
The objectives of this work were to evaluate effects of replacing corn by cassava by-product meal, in diets of Saanen lactating goats, on potencial, effective and corrected effective degradability of diets with steers, and on ruminal $\mathrm{pH}$ and ruminal ammonia, plasma urea nitrogen (PUN) and milk urea nitrogen (MUN) concentrations in lactating goats. Two steers and four multiparous goats fitted with ruminal cannula and 100 days in milking were used. The design was a 4 x 4 Latin square and treatments as following: 0, 33, 67 and $100 \%$ replacement of corn by cassava by-product meal. Rations degradability was determined using in situ technique. Potential degradability of experimental diets showed small variation for dry matter (DM), crude protein (CP) and starch (S) but effective and corrected effective degradability increased as corn was replaced by cassava by-product meal. Treatments did not influence ruminal pH and ruminal ammonia, PUN and MUN concentrations. There was a positive correlation $(\mathrm{P}<0.05 ; \mathrm{r}=0.9288)$ between $\mathrm{PUN}$ and MUN concentrations, making possible PUN estimation from the equation: PUN (mg/dL) $=0.7672 * \mathrm{MUN}(\mathrm{mg} / \mathrm{dL})+7.4894$. These results permit to conclude that cassava by-product meal can be used in lactating goat diets, as $30 \%$ of DM, in total replacing of corn, without problems in ruminal fermentation and protein metabolism.
\end{abstract}

Key Words: cassava, dairy goats, degradability, rumen, urea

\section{Introdução}

O fato de os ingredientes dietéticos serem primeiramente submetidos a uma fermentação microbiana, tornando o processo digestivo em ruminantes altamente complexo e dependente de interações entre o animal, os microrganismos e os alimentos, exige métodos específicos para avaliar os nutrientes absorvidos (Harmon \& Richards, 1997).

Informações obtidas em experimentos utilizando a técnica in situ geram dados que permitem uma combinação mais racional de suplementos protéicos

\footnotetext{
1 Parte da tese da primeira autora apresentada à Universidade Estadual de Maringá para a obtenção do título de "Mestre em Zootecnia". ${ }^{2}$ Professor do Departamento de Zootecnia - UEM Av. Colombo, 5790. CEP 87020-900. Maringá-PR. E.mail: afbranco@uem.br; fafmacedo@uem.br; cralcalde@wnet.com.br

${ }^{3}$ Estudante de Pós Graduação em Zootecnia - UEM Av. Colombo, 5790. CEP 87020-900. Maringá-PR. E.mail: gfmouro@hotmail.com; cylene25@hotmail.com; pauloprohmann@yahoo.com.br

${ }^{4}$ Estudante de Graduação em Zootecnia - Bolsista PIBIC - UEM Av. Colombo, 5790. CEP: 87020-900. Maringá-PR. E.mail: roseaferreira@bol.com.br

${ }^{5}$ Pesquisador do CNPq.
} 
e energéticos, aumentando, assim, a eficiência de utilização dos nutrientes no rúmen e, como conseqüência, melhoram o desempenho animal (HerreraSaldana et al., 1990b). Grãos e subprodutos agroindustriais variam amplamente na disponibilidade ruminal de seus nutrientes, afirmaram Batajoo \& Shaver (1998), ao estudarem a degradabilidade do amido de alguns alimentos, demonstrando a importância do estudo da degradabilidade dos alimentos nos ensaios de digestão.

A síntese de proteína microbiana no rúmen depende da disponibilidade de carboidratos e de amônia no rúmen. Segundo Van Soest (1994), a energia é o fator mais limitante à síntese de proteína microbiana.

A amônia ruminal é produzida a partir da degradação dos compostos nitrogenados no rúmen e altos níveis indicam excesso de proteína dietética ou degradada, ou, ainda, falta de sincronização entre as fontes de carboidratos e nitrogênio (Baker et al., 1995).

Overton et al. (1995) avaliaram o efeito da substituição do milho pela cevada, sobre o metabolismo ruminal, em vacas em lactação. Verificou-se efeito linear negativo $(\mathrm{P}<0,05)$ sobre a concentração de amônia e o pH no fluído ruminal, ou seja, à medida que a proporção de cevada aumentava na dieta, o pH e as concentrações de amônia diminuíam. Quanto mais rápida for a degradação dos alimentos ricos em amido, maior é o acúmulo de ácido láctico no rúmen e maior é a queda no $\mathrm{pH}$. A queda do $\mathrm{pH}$ inibe o crescimento das bactérias que degradam a celulose, podendo, desta forma, ocorrer prejuízo na digestão da fração fibrosa da dieta.

Khorasani et al. (1994) verificaram que a concentração de amônia ruminal não foi influenciada pela sincronização da dieta. No entanto, outros autores verificaram que a concentração de amônia ruminal tende a diminuir com a sincronização da taxa de degradação das fontes de carboidratos e nitrogênio, indicando melhor aproveitamento do nitrogênio disponível pelos microrganismos (Schimidely et al., 1996; Yang et al., 1997; Casper et al., 1999; Philippeau et al., 1999).

A uréia plasmática é sintetizada a partir da amônia produzida pela degradação dos compostos nitrogenados no rúmen e absorvida pela parede desse órgão. As concentrações de uréia no leite são altamente correlacionadas com as concentrações plasmáticas de uréia (Baker et al., 1995; Butler et al., 1996). Os fatores nutricionais que favorecem altos níveis de uréia no leite são o excesso de nitrogênio degradável no rúmen, aumento de proteína, chegando aos órgãos pós-rúmen, ou falta de sincronização nas taxas de degradação ruminal entre as fontes de nitrogênio e energia (Baker et al., 1995).

O objetivo deste trabalho foi avaliar o efeito da substituição do milho pela farinha de mandioca de varredura, em dietas de cabras Saanen em lactação, sobre a degradabilidade potencial, efetiva e efetiva corrigida das rações, bem como sobre o pH ruminal e as concentrações de amônia ruminal, uréia plasmática e uréia no leite.

\section{Material e Métodos}

Este experimento foi realizado no setor de Nutrição de Ruminantes da Fazenda Experimental de Iguatemi, campus da Universidade Estadual de Maringá, localizada no distrito de Iguatemi, e no Laboratório de Análises de Alimentos e Nutrição Animal - UEM, no período de outubro de 2000 a fevereiro de 2001.

Foram utilizadas quatro cabras da raça Saanen, canuladas no rúmen e pesando, em média, $50 \mathrm{~kg}$. As cabras estavam há 100 dias em lactação, com produção média de $2 \mathrm{~kg}$ de leite/dia e foram alojadas em gaiolas de metal com piso ripado de madeira, com bebedouro e comedouro individuais.

Os animais foram alimentados duas vezes ao dia, às 8 e 16 h e receberam água limpa à vontade; além disso, foi mantido um controle higiênico e sanitário rigoroso dos animais, sendo as gaiolas e animais higienizados duas vezes por dia. As cabras foram ordenhadas duas vezes por dia, às $8 \mathrm{~h} 30$ e $15 \mathrm{~h}$.

Os animais receberam dieta balanceada, de forma a atender às exigências de mantença e lactação segundo o AFRC (1993), com uma relação volumoso:concentrado de 40:60, sendo o volumoso o feno de alfafa. O delineamento experimental utilizado foi o quadrado latino $4 \times 4$. A composição das rações experimentais se encontra na Tabela 1. Os tratamentos consistiram na substituição no concentrado do milho pela farinha de mandioca de varredura, sendo: T0 = volumoso + ração com $0 \%$ de substituição T33 = volumoso + ração com $33 \%$ de substituição T67 = volumoso + ração com $67 \%$ de substituição T100 = volumoso + ração com $100 \%$ de substituição

Os períodos experimentais tiveram a duração de 14 dias. As amostras de líquido ruminal para a determinação de $\mathrm{N}$-amoniacal e $\mathrm{pH}$ foram colhidas o 4 - dia do período experimental, das $6 \mathrm{~h}$ às $20 \mathrm{~h}$ a cada 2 horas no período. 
As amostras de leite foram coletadas duas vezes por dia (11ํㅜ $12^{\mathrm{o}}$ e $13^{\circ}$ dias), em horários regulares, $8 \mathrm{~h} 30$ e $15 \mathrm{~h}$, preservadas com 2-bromo-2nitropropano-1,3diol (BRONOPOL) e refrigeradas a $4^{\circ} \mathrm{C}$. As amostras da manhã e tarde foram compostas para o $11^{\mathrm{o}}, 12^{\mathrm{o}}$ e $13^{\mathrm{o}} \mathrm{\text {dias}}$. Posteriormente, foram centrifugadas a $3500 \mathrm{x}$ g por 15 minutos a $22^{\circ} \mathrm{C}$ e mantidas no refrigerador por 24 horas, tempo suficiente para retirar a camada sobrenadante, representa-

Tabela 1 - Composição percentual, química e teores de NDT das dietas experimentais (\% na MS)

Table 1 - Percentual, chemical and TDN composition of the experimental diets (\% dry matter)

\begin{tabular}{|c|c|c|c|c|}
\hline $\begin{array}{l}\text { Alimentos } \\
\text { Feedstuffs }\end{array}$ & $\mathrm{T}_{0}{ }^{1}$ & $\mathrm{~T}_{33}$ & $\mathrm{~T}_{67}$ & $\mathrm{~T}_{100}$ \\
\hline $\begin{array}{l}\text { Feno de alfafa } \\
\text { Alfalfa hay }\end{array}$ & 40,00 & 40,00 & 40,00 & 40,00 \\
\hline $\begin{array}{l}\text { Farinha de mandioca } \\
\text { de varredura }\end{array}$ & 0,00 & 10,02 & 19,98 & 30,00 \\
\hline $\begin{array}{l}\text { Cassava meal } \\
\text { Milho }\end{array}$ & 30,00 & 19,98 & 10,02 & 0,00 \\
\hline $\begin{array}{l}\text { Corn } \\
\text { Casca de soja } \\
\text { Soybean hulls }\end{array}$ & 15,00 & 15,00 & 15,00 & 15,00 \\
\hline $\begin{array}{l}\text { Polpa cítrica desidratada } \\
\text { Citrus pulp dehydrated }\end{array}$ & 7,50 & 7,50 & 6,60 & 6,60 \\
\hline $\begin{array}{l}\text { Farelo de soja } \\
\text { Soybean meal }\end{array}$ & 0,60 & 0,90 & 0,90 & 1,50 \\
\hline $\begin{array}{l}\text { Uréia } \\
\text { Urea }\end{array}$ & 0,00 & 0,24 & 0,54 & 0,72 \\
\hline $\begin{array}{l}\text { Óleo de soja } \\
\text { Soybean oil }\end{array}$ & 1,80 & 1,98 & 2,40 & 2,70 \\
\hline $\begin{array}{l}\text { Sal } \\
\text { Salt }\end{array}$ & 0,48 & 0,48 & 0,48 & 0,48 \\
\hline $\begin{array}{l}\text { Minerais } \\
\text { Minerals }\end{array}$ & 1,50 & 1,50 & 1,50 & 1,50 \\
\hline $\begin{array}{l}\text { Inerte } \\
\text { Inert } \\
\text { Nutrientes }\end{array}$ & 3,12 & 2,40 & 2,58 & 1,50 \\
\hline $\begin{array}{l}\text { NDT } \\
T D N\end{array}$ & 73,89 & 73,86 & 73,28 & 73,72 \\
\hline $\begin{array}{l}\mathrm{PB} \\
P B\end{array}$ & 16,22 & 16,24 & 16,24 & 16,24 \\
\hline $\begin{array}{l}\text { Proteína degradável } \\
\text { (\% da PB) } \\
\text { Degradable protein }\end{array}$ & 61,41 & 62,97 & 64,00 & 65,71 \\
\hline $\begin{array}{l}\text { FDN } \\
N D F\end{array}$ & 29,76 & 29,52 & 29,03 & 28,85 \\
\hline $\begin{array}{l}\text { Extrato etéreo } \\
\text { Ether extract }\end{array}$ & 4,95 & 4,81 & 4,89 & 4,87 \\
\hline $\begin{array}{ll}\mathrm{Ca} \\
\mathrm{P}\end{array}$ & 1,01 & 1,01 & 1,00 & 1,00 \\
\hline
\end{tabular}

${ }^{1} \mathrm{~T}_{0}$ : dieta com $0 \%$ de substituição do milho pela farinha de varredura; $\mathrm{T}_{33}$ : dieta com $33 \%$ de substituição; $\mathrm{T}_{67}$ : dieta com $67 \%$ de substituição; $T_{100}$ : dieta com $100 \%$ de substituição.

${ }^{1} T_{0}$ : diet with $0 \%$ replacement corn by cassava by-product meal; $T_{33}$ : diet with $33 \%$ replacement; $T_{67}$ : diet with $67 \%$ replacement; $T_{100}$ : diet with $100 \%$ replacement. da pela gordura. O leite desengordurado foi analisado para concentração de uréia pelo método enzimático (urease/glutamato desidrogenase), segundo Talke e Schubert (1965), utilizando o analisador automático Merch Vitalab Selectra ${ }^{\circledR} 2$.

Amostras heparinizadas de sangue foram coletadas da veia jugular de cada animal, duas vezes ao dia, às 10 e $18 \mathrm{~h}, \operatorname{nos} 11^{\mathrm{O}}, 12^{\mathrm{o}}$ e $13 \stackrel{0}{\mathrm{o}}$ dia do período experimental. Logo após as coletas, as amostra foram centrifugadas a $3500 \mathrm{x}$ g por 15 minutos. $\mathrm{O}$ plasma foi removido e, em seguida, congelado, sendo, posteriormente, analisado para concentração de uréia pela mesma metodologia que o leite desengordurado.

As degradabilidades da matéria seca, proteína bruta e amido dos alimentos foram estimadas pela técnica in situ dos sacos de náilon, a partir de amostras incubadas em dois bovinos da raça Holandês, em delineamento em blocos casualizados. A degradabilidade de cada dieta foi estimada considerando a porcentagem de participação de cada alimento na mesma. Sacos de monofilamento de poliéster, lacrados pelo calor, fabricados em náilon (ANKONBAR DIAMOND, INC®., Parma Idaho - USA) foram utilizados para a incubação ruminal. As dimensões do saco foram de $10 \mathrm{~cm}$ x $17 \mathrm{~cm}$, com diâmetro de poros de 53 micra. Os alimentos concentrados e o feno de alfafa foram moídos em peneira com crivo de $3 \mathrm{~mm}$. Aproximadamente, $7 \mathrm{~g}$ de amostra (base na MS) foram colocados em cada saco, fechando-os e atando-os com uma argola de metal fixada com borracha. Nos dias de incubação, os sacos foram presos, em triplicata, exceto a farinha de varredura, quintuplicata, aos aros de uma corrente de ferro inoxidável, ligada a uma âncora (600 g) em sua extremidade, a qual permaneceu suspensa por um fio de náilon de $60 \mathrm{~cm}$ de comprimento, à fístula ruminal.

Os tempos de incubação empregados tiveram a duração de 72, 48, 24, 18, 12, 8, 6, 4, 2, e 0 horas. As amostras que tiveram período de incubação de 2 horas foram retiradas às $10 \mathrm{~h}$ do dia 1 de incubação, já as de 72, 48, 24 e 18 horas foram retiradas às $8 \mathrm{~h}$ do dia 4 de incubação. As amostras dos horários 12, 8,6 e 4 horas, foram incubadas no dia 4 e retirados às $20 \mathrm{~h}$ do mesmo dia.

Após a remoção, os sacos foram lavados em água corrente e, posteriormente, em máquina de lavar, em cinco ciclos de $10 \mathrm{~min}$. Os sacos com as amostras do tempo zero foram colocados em banhomaria a $39^{\circ} \mathrm{C}$ por $60 \mathrm{~min}$ e, depois, lavados.

Após serem lavados, os sacos foram submetidos 
à secagem em estufa de ventilação forçada, a $55^{\circ} \mathrm{C}$, por 72 horas. A porcentagem de desaparecimento por tempo de incubação foi calculada pela proporção de alimento que restou nos sacos, após a incubação ruminal.

A degradabilidade da MS, PB e do amido foi calculada por intermédio da equação descrita por Mehrez \& Orskov (1977):

$$
\mathrm{p}=\mathrm{a}+\mathrm{b}(1-\mathrm{e}-\mathrm{ct})
$$

em que: $\mathrm{p}=$ taxa de degradação no tempo t; $\mathrm{a}=$ intercepto representando a porção prontamente solúvel no rúmen; $b$ = fração insolúvel, mas potencialmente degradável; $\mathrm{c}=$ taxa constante de degradação da fração $b ; t=$ tempo de incubação; $a+b \leq 100$

Os parâmetros não lineares a, b e c foram estimados pelo programa SAEG (1983). A degradabilidade efetiva (DE) da MS, PB e do amido foi calculada por intermédio da equação descrita por Orskov \& McDonald (1979):

$$
\mathrm{D} \mathrm{E}=\mathrm{a}+(\mathrm{bc} / \mathrm{c}+\mathrm{k})
$$

em que: $\mathrm{k}=$ taxa estimada da passagem dos sólidos no rúmen; Os demais parâmetros foram descritos na equação anterior.

A degradabilidade efetiva da MS, PB e amido foi estimada para cada alimento, para as taxas de passagem dos sólidos de $5 \% / \mathrm{h}$ que é atribuída, respectivamente, ao nível médio de ingestão alimentar (AFRC, 1993), adotado no experimento. Ainda foi determinada a degradabilidade efetiva corrigida para a fração solúvel em água da MS, PB e amido, segundo a metodologia descrita por Huntington \& Givens (1997).

Foram ainda estimadas as correlações entre as concentrações de uréia plasmática e do leite. As correlações foram estimadas pelo método de Pearson, por intermédio do programa SAEG (1983), e consideradas significativas se $\mathrm{P}<0,05$.

\section{Resultados e Discussão}

Os parâmetros a (fração solúvel), b (fração potencialmente degradável) e c (taxa de degradação da fração b) a degradabilidade potencial, a degradabilidade efetiva e a degradabilidade efetiva corrigida das dietas experimentais, para a taxa de passagem de 5\%/h são mostrados na Tabela 2 e a curva da degradação potencial da MS, PB e amido das dietas experimentais estão nas Figuras 1, 2 e 3.

A fração a das dietas variou de 29,9 a $37,2 \%$ para a MS, de 37,8 a $44,8 \%$ para a PB e de 29,2 a $40,9 \%$ para o amido, em ordem numericamente crescente, conforme o milho foi substituído pela farinha de varredura na ração concentrada. A fração b apresentou comportamento inverso, ou seja, os valores variaram de 52,8 a $45,4 \%$ para a MS, de 50,2 a 41,6\% para a PB e de 55,4 a $45,1 \%$ para o amido, em ordem numericamente decrescente à inclusão de farinha de varredura nas dietas.

Os valores de c das dietas experimentais ficaram entre 4,52 e 11,20\%/h para a MS, entre 4,31 e $6,50 \% / \mathrm{h}$ para a PB e entre 5,72 e $13,71 \% / \mathrm{h}$ para o amido, acompanhando o comportamento da fração a.

Apesar de a degradabilidade potencial das dietas experimentais ter tido pequena variação para a MS $(82,0-82,9 \%)$, PB $(86,4-88,0 \%)$ e amido $(84,4-$ $85,3 \%)$, a degradabilidade efetiva da MS ficou entre 55,1 e 64, 3\%; a da PB, 61,0 e 68,1\%; e a do amido, 59,1 e $68,8 \%$, aumentando com a substituição do milho pela farinha de varredura de mandioca. A degradabilidade da PB das dietas obtida neste experimento ficou próxima à obtida por estimativas, utilizando valores de tabelas (NRC, 1996), que variaram de 61,4 a $65,7 \%$ (Tabela 1 ).

Uma das limitações da técnica in situ de degradabilidade é decorrente da perda física de pequenas partículas, através dos poros das bolsas

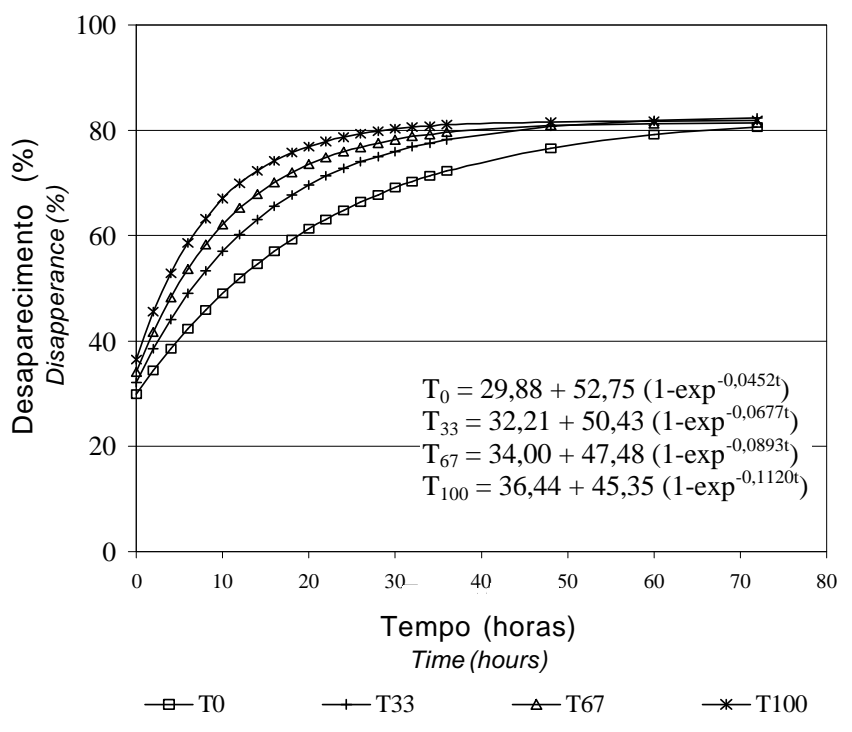

Figure 1 - Curva da degradação potencial da MS das dietas experimentais.

Figure 1 - Potential degradation curve of dry matter of the experimental diets. 


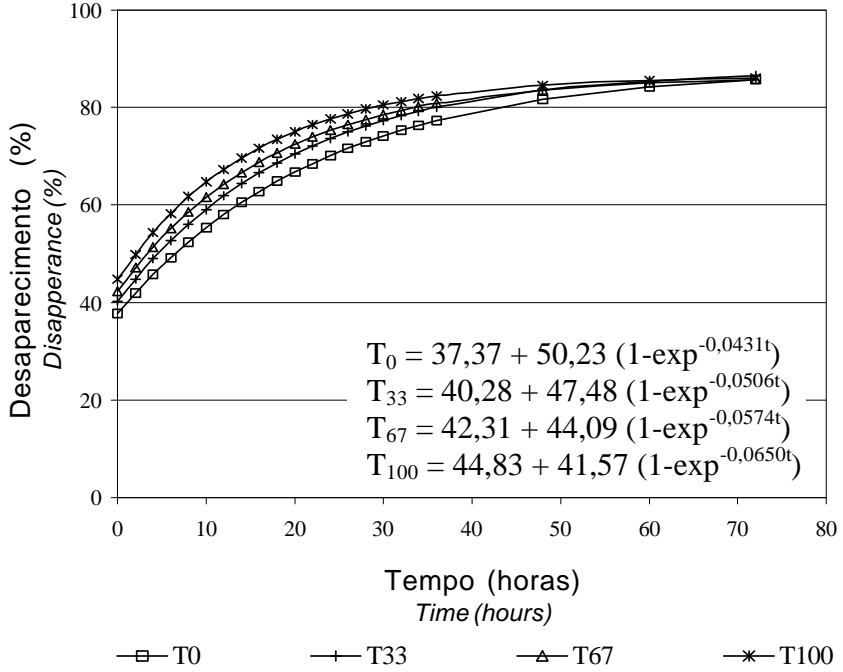

Figura 2 - Curva da degradação potencial da PB das dietas experimentais.

Figure 2 - Potential degradation curve of crude protein of the experimental diets.

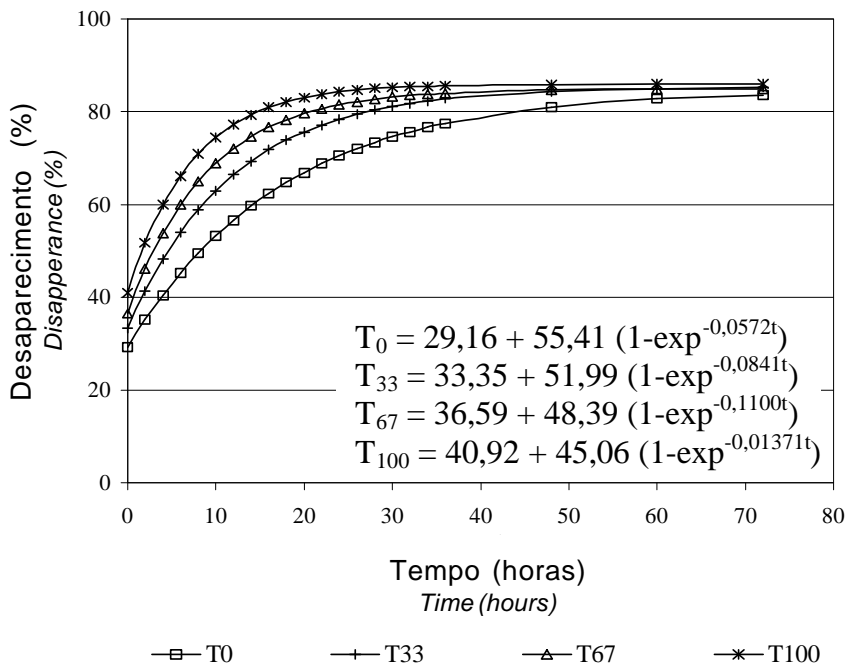

Figura 3 - Curva da degradação potencial do amido das dietas experimentais.

Figure 3 - Potential degradation curve of starch of the experimental diets.

Tabela 2 - Fração solúvel (a) e potencialmente degradável (b), taxa de degradação da fração b (c), degradabilidade potencial (DP), degradabilidade efetiva (DE) e degradabilidade efetiva corrigida (DEc) a uma taxa de passagem de $5 \%$, para a matéria seca, proteína bruta e amido das dietas experimentais determinadas em bovinos

Table 2 - Soluble fraction (a), potentially degradable fraction (b), fraction b degradation rate (c), potential degradability (PD), effective degradability (ED) and corrected effective degradability (cED), of diets dry matter, crude protein and starch, on passage rate of $5 \% / h$ determined with steers

\begin{tabular}{|c|c|c|c|c|c|c|}
\hline & $\begin{array}{c}\mathrm{a} \\
(\%)\end{array}$ & $\begin{array}{c}\mathrm{b} \\
(\%)\end{array}$ & $\begin{array}{c}\mathrm{c} \\
(\% / \mathrm{h})\end{array}$ & $\begin{array}{c}\mathrm{DP}(P D) \\
(\%)\end{array}$ & $\begin{array}{c}\mathrm{DE}(E D) \\
(\%)\end{array}$ & $\begin{array}{c}\operatorname{DEc}(c E D) \\
(\%)\end{array}$ \\
\hline & \multicolumn{6}{|c|}{ Matéria seca } \\
\hline $\mathrm{T}_{0}^{1}$ & 29,9 & 52,8 & 4,52 & 82,6 & 55,1 & 48,2 \\
\hline $\mathrm{T}_{33}$ & 32,5 & 50,4 & 6,77 & 82,9 & 58,4 & 52,0 \\
\hline $\mathrm{T}_{67}^{33}$ & 34,5 & 47,5 & 8,93 & 82,0 & 60,9 & 55,0 \\
\hline $\mathrm{T}_{100}$ & 37,2 & 45,4 & 11,20 & 82,5 & 64,3 & 58,9 \\
\hline & \multicolumn{6}{|c|}{$\begin{array}{c}\text { Proteína bruta } \\
\text { Crude protein }\end{array}$} \\
\hline $\mathrm{T}_{0}$ & 37,8 & 50,2 & 4,31 & 88,0 & 61,0 & 52,0 \\
\hline $\mathrm{T}_{33}^{0}$ & 40,3 & 47,5 & 5,06 & 87,8 & 63,6 & 55,2 \\
\hline $\mathrm{T}_{67}^{33}$ & 42,3 & 44,1 & 5,74 & 86,4 & 65,4 & 57,6 \\
\hline $\mathrm{T}_{100}^{0 /}$ & 44,8 & 41,6 & 6,50 & 86,4 & 68,1 & 60,9 \\
\hline & \multicolumn{6}{|c|}{$\begin{array}{l}\text { Amido } \\
\text { Starch }\end{array}$} \\
\hline $\mathrm{T}_{0}$ & 29,2 & 55,4 & 5,72 & 84,6 & 59,1 & 57,0 \\
\hline $\mathrm{T}_{33}$ & 33,4 & 52,0 & 8,41 & 85,1 & 62,6 & 60,3 \\
\hline $\mathrm{T}_{67}^{53}$ & 36,6 & 48,4 & 11,00 & 84,4 & 65,0 & 62,5 \\
\hline $\mathrm{T}_{100}^{0 /}$ & 40,9 & 45,1 & 13,71 & 85,3 & 68,8 & 66,0 \\
\hline
\end{tabular}

${ }_{1}^{1} \mathrm{~T}_{0}$ : dieta com $0 \%$ de substituição do milho pela farinha de varredura; $\mathrm{T}_{33}$ : dieta com $33 \%$ de substituição; $\mathrm{T}_{67}$ : dieta com $67 \%$ de substituição; $\mathrm{T}_{100}$ : dieta com $100 \%$ de substituição.

${ }^{1} T_{0}$ : diet with $0 \%$ replacement corn by cassava by-product meal; $T_{33}$ : diet with 33\% replacement; $T_{67}$ : diet with $67 \%$ replacement; $T_{100}$ : diet with $100 \%$ replacement. 
(Huntington \& Givens, 1995). Os valores de "tempo zero", determinados pela lavagem das bolsas juntamente com o substrato mas, sem a incubação ruminal e que serão utilizados para estimativas da fração solúvel, possuem dois componentes: o primeiro, a fração solúvel em água propriamente dita e o segundo, a perda física de pequenas partículas através da porosidade das bolsas.

As estimativas da degradabilidade efetiva corrigida mostraram valores entre 48,20 e $58,89 \%$ para a MS, entre 52,0 e $60,9 \%$ para a PB e entre 57 , 0 e $66,0 \%$, para o amido e foram crescentes conforme o milho foi substituído pela farinha de mandioca de varredura. Segundo Huntington \& Givens (1997), as estimativas da degradabilidade efetiva e a efetiva corrigida foram significativamente diferentes, provavelmente porque as partículas que foram perdidas, através da porosidade da bolsa, são componentes da fração potencialmente degradável e estarão submetidas à uma taxa de degradação, ou, ainda, são componentes da fração não degradável.

Os dados de $\mathrm{pH}$ e $\mathrm{NH}_{3}$-ruminal se encontram na Tabela 3. A substituição do milho pela farinha de mandioca de varredura não influenciou $(\mathrm{P}>0,05)$ mudanças no $\mathrm{pH}$ e no $\mathrm{NH}_{3}$-ruminal ( $\left.\mathrm{mg} / \mathrm{dL}\right)$, com valores médios de 6,37 e 16,39, respectivamente. Com relação ao $\mathrm{pH}$ ruminal estes dados confirmam os obtidos por Caldas Neto (1999), que, trabalhando com as mesmas fontes de amido, verificou não haver diferença para este parâmetro médio entre as dietas. Entretanto, para a concentração de $\mathrm{NH}_{3}$ ruminal, os dados discordam de Caldas Neto (1999), que verificaram menor concentração $(\mathrm{P}<0,05)$ com a utilização da farinha de mandioca de varredura.

$\mathrm{O}$ valor médio de $\mathrm{pH}$ encontrado neste experimento foi de 6,37 e está próximo ao encontrado por
Gonçalves et al. (2000) que foi de 6,25, em um mesmo nível de ingestão de volumoso, com cabras da raça Alpina. $\mathrm{O}$ pH ruminal de vacas, alimentadas com dietas à base de milho, não diferiu das alimentadas com farinha de mandioca de varredura, apesar dos animais que consumiram a farinha terem apresentado valores menores de concentração de amônia ruminal $(15,3 \mathrm{mg} / \mathrm{dL})$, em relação aos que consumiram milho $(22,34 \mathrm{mg} / \mathrm{dL})$ (Simas et al., 2000).

Herrera-Saldana et al. (1990a) e pesquisadores citados por Nocek \& Taminga (1991) preconizam a utilização de fontes, observando-se a taxa de sincronização da degradação ruminal do amido e nitrogênio, para a obtenção de um ambiente ruminal que proporcione uma eficiente utilização do nitrogênio disponível para o crescimento microbiano.

A utilização de alimentos com rápidas taxas de degradação do amido, podem em dietas de ruminantes levar à queda no $\mathrm{pH}$ ruminal (Nocek \& Tamminga, 1991), produzindo uma condição prejudicial ao crescimento das bactérias que degradam a celulose, tendo como resultado, a redução na digestão da fração fibrosa da dieta.

As concentrações de uréia no plasma e no leite são consideradas bons indicadores do metabolismo e ingestão de proteína em vacas leiteiras e, atualmente, são utilizados como ferramentas para a avaliação de dietas.

Os dados relativos às concentrações de uréia no plasma (UP) e no leite (UL) são mostradas na Tabela 4.

Os níveis de uréia no plasma e no leite não foram influenciados pelas dietas experimentais, com valores médios de 38,30 e 36,87 (mg/dL), respectivamente, mostrando que, a utilização de fontes de amido com diferentes taxas de degradação ruminal não interferiram nestes indicadores do metabolismo do nitrogênio. Os resultados confirmam os de Schimidely et al.

Tabela 3 - Média, regressão e coeficiente de determinação para as concentrações de nitrogênio- $\mathrm{NH}$ ( $\left(\mathrm{N}-\mathrm{NH}_{3}\right)$ e pH ruminal

Table 3 - Mean, regression equations and determination coefficients $\left(R^{2}\right)$ for ruminal concentration of $\mathrm{NH}_{3}-n$ itrogen $\left(\mathrm{NH}_{3}-\mathrm{N}\right)$ and $p H$

\begin{tabular}{|c|c|c|c|c|c|c|c|}
\hline & \multicolumn{4}{|c|}{$\begin{array}{l}\text { Tratamentos } \\
\text { Treatments }\end{array}$} & \multirow[t]{2}{*}{$\begin{array}{l}\text { Regressão } \\
\text { Regression }\end{array}$} & \multirow[t]{2}{*}{$\mathrm{R}^{2}$} & \multirow[t]{2}{*}{$\mathrm{CV} \%$} \\
\hline & $\mathrm{T}_{0}$ & $\mathrm{~T}_{33}$ & $\mathrm{~T}_{67}$ & $\mathrm{~T}_{100}$ & & & \\
\hline $\begin{array}{l}\mathrm{N}-\mathrm{NH}_{3}(\mathrm{mg} / \mathrm{dL}) \\
\mathrm{NH}_{3}-\mathrm{N}\end{array}$ & 15,77 & 18,45 & 16,03 & 15,30 & $Y=16,39$ & NS & 33,66 \\
\hline $\begin{array}{l}\mathrm{pH}^{3} \\
\mathrm{pH}\end{array}$ & 6,34 & 6,42 & 6,39 & 6,32 & $Y=6,37$ & NS & 3,29 \\
\hline
\end{tabular}


Tabela 4 - Média, regressão e coeficiente de determinação para as concentrações de uréia plasmática e do leite Table 4 - Mean, regression equations and determination coefficients $\left(R^{2}\right)$ for plasma urea (PU) and milk urea (MU)

\begin{tabular}{|c|c|c|c|c|c|c|c|}
\hline & \multicolumn{4}{|c|}{$\begin{array}{l}\text { Tratamentos } \\
\text { Treatments }\end{array}$} & \multirow[t]{2}{*}{$\begin{array}{l}\text { Regressão } \\
\text { Regression }\end{array}$} & \multirow[t]{2}{*}{$\mathrm{R}^{2}$} & \multirow[t]{2}{*}{ CV\% } \\
\hline & $\mathrm{T}_{0}$ & $\mathrm{~T}_{33}$ & $\mathrm{~T}_{67}$ & $\mathrm{~T}_{100}$ & & & \\
\hline $\begin{array}{l}\text { Uréia plasmática (mg/dL) } \\
P U\end{array}$ & 37,08 & 39,96 & 36,46 & 39,71 & $Y=38,30$ & NS & 2,07 \\
\hline $\begin{array}{l}\text { Uréia do leite (mg/dL) } \\
M U\end{array}$ & 36,66 & 36,16 & 36,00 & 38,66 & $Y=36,87$ & NS & 19,72 \\
\hline
\end{tabular}

(1996) que, trabalhando com sincronização das taxas de degradação de amido e do nitrogênio, em dietas de cabras, verificaram que a concentração de UP não diferiu entre os tratamentos, com valor médio de 36 $\mathrm{mg} / \mathrm{dL}$, próximo ao encontrado neste trabalho. A taxa da degradação ruminal dos carboidratos não estruturais $(6,04,6,98$ e $7,94 \% / h)$ teve um efeito linear negativo sobre os níveis de UL (Lykos \& Varga, 1997), embora estas variáveis pareçam estar mais relacionadas com os níveis e a degradabilidade da proteína dietética (HOFet al., 1997). A degradabilidade ruminal da proteína tem um impacto direto sobre as concentrações de amônia ruminal, como também, sobre a concentração de uréia no leite (Schepers \& Meijer, 1998).

Os valores de UP e UL são altamente correlacionados com os teores de PB dietéticos, entretanto, os níveis de energia dietéticos não influenciaram variações significativas destes parâmetros em ovelhas (Cannas et al., 1998). A hipótese de que a degradabilidade ruminal do amido estaria relacionada com níveis de uréia no plasma e no leite é devido à constatação de que a disponibilidade de substrato para a fermentação ruminal, em taxas sincronizadas com a liberação do nitrogênio, pode melhorar a utilização do nitrogênio disponível na forma de amônia pelos microrganismos, mantendo as concentrações mais baixas de amônia ruminal (García et al., 2000) e, desta forma, influenciar a concentração de UP e, como conseqüência, a de UL.

Neste experimento, uma característica inerente às dietas experimentais deve ser ressaltada, ou seja, as duas fontes de amido utilizadas possuíam diferentes concentrações de proteína bruta, o milho com $9,8 \%$ e a farinha de mandioca de varredura com
1,9\%. À medida que o milho foi substituído pela farinha, houve a necessidade de adicionar uréia às dietas, a fim de torná-las isoproteicas, fazendo com que a degradabilidade ruminal da proteína das dietas, tanto a estimada por dados de tabelas (NRC, 1996; Tabela 1), como a obtida in situ (Tabela 2; Figura 2) aumentasse, acompanhando de forma proporcional a degradabilidade do amido (Tabela 2; Figura 3). Dessa forma, a disponibilidade ruminal dos substratos energéticos e protéicos foi semelhante nas dietas estudadas, o que pode ter propiciado uma utilização equivalente das fontes de energia de lenta e de rápida degradação, explicada pela falta de diferença significativa entre os tratamentos, com relação ao metabolismo do nitrogênio, neste caso, as concentrações de UP, UL e amônia ruminal.

A correlação entre UP e UL está demonstrada na Figura 4, bem como o coeficiente de determinação e a equação de regressão linear.

Observou-se alta correlação linear $(r=0,9288)$ entre as concentrações no plasma e no leite. Estes dados confirmam os obtidos por Baker et al. (1995), Butler et al. (1996), Broderich et al. (1997) e Rodriguez et al. (1997), que também encontraram alta correlação entre estas duas variáveis.

A uréia presente na circulação sangüínea tem a capacidade de se difundir livremente para o leite. Dessa forma, é possível estimar a concentração da UP medindo a UL, pois todos os fatores que influenciam a UP também influenciarão a concentração de UL. O leite é um fluido coletado com mais facilidade que o sangue e, na maioria das propriedades leiteiras, isto é realizado pelo menos duas vezes por dia, tornando fácil a obtenção de estimativas dos níveis sangüíneos de uréia a partir de UL, já que os níveis de 


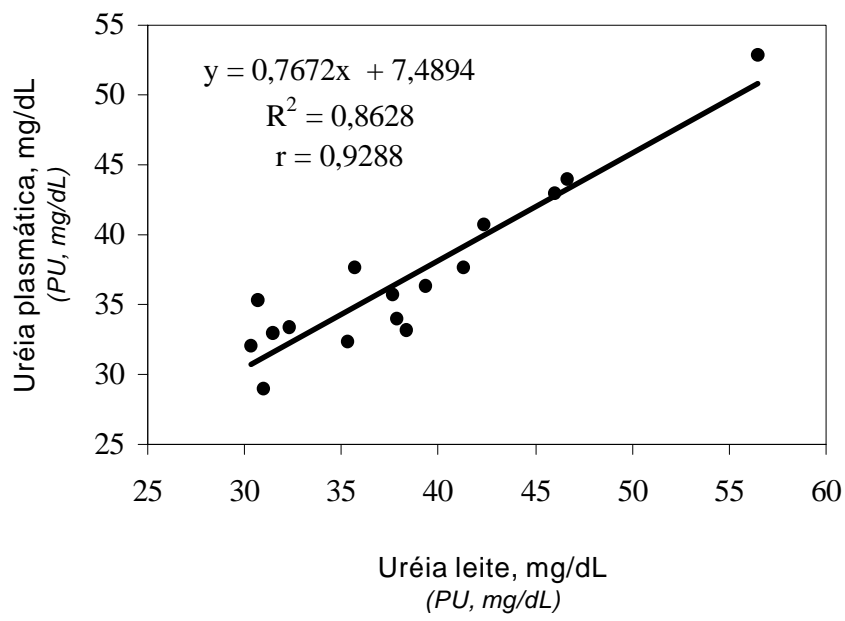

Figura 4 - Correlação entre a uréia do leite e a plasmática.

Figure 4 - Correlation between milk (MU) and plasma (PU) urea.

uréia são ferramentas importantes para o monitoramento da nutrição protéica em rebanhos leiteiros (Hof et al, 1997).

\section{Conclusões}

A inclusão de farinha de mandioca de varredura em substituição ao milho, em dietas de cabras em lactação, não influenciou o $\mathrm{pH}$ ruminal, bem como as concentrações de uréia plasmática, uréia do leite e $\mathrm{NH}_{3}$-ruminal. Houve uma correlação positiva entre as concentrações de uréia plasmática e a uréia do leite.

\section{Literatura Citada}

AGRICULTURAL AND FOOD RESEARCH COUNCIL AFRC. Energy and protein requirements of ruminants. Wallington: CAB International, 1993. 159p.

BAKER, L.D.; FERGUSON., J.D.; CHALUPA, W. Reponses in urea and true protein of milk to different protein feeding schemes for dairy cows. Journal of Dairy Science, v.78, p.2424-2434, 1995.

BATAJOO, K.K.; SHAVER, R.D. In situ dry matter, crude protein, and starch degradabilities of selected grains and byproduct feeds. Animal Feed Science and Technology, v.71, n.1-2, p.165-176, 1998.

BRODERICK, G.A.; CLAYTON, M.K. A statistical evaluation of animal and nutritional factors influencing concentrations of milk urea nitrogen. Journal of Dairy Science, v.80, p.2964-2971, 1997.

BUTLER, W.R.; CALAMAN, J.J.; BEAM, S.W. Plasma and milk urea nitrogen in relation to pregnancy rate in lactating dairy cattle. Journal of Animal Science, v.74, p.858-865. 1996.
CALDAS NETO, S.F. Digestibilidade parcial e total, parâmetros ruminais e degradabilidade de rações com mandioca e resíduos das farinheiras. Maringá: Universidade Estadual de Maringá, 1999. 66p. Dissertação (Mestrado em Zootecnia) - Universidade Estadual de Maringá, 1999.

CANNAS, A.; PES, A.; MANCUSO, R. et al. Effect of dietary energy and protein concentration on the concentration of milk urea nitrogen in dairy ewes. Journal of Dairy Science, v.81, p.499-508, 1998.

CASPER, D.P.; MAIGA, H.A.; BROUK, M.J. et al. Synchronization of carbohydrate and protein sources on fermentation and passage rates in dairy cows. Journal of Dairy Science, v.82, p.1779-1790, 1999.

GARCÍA, S.C.; SANTINI, F.J.; ELIZALDE, J.C. Sites of digestion and bacterial protein synthesis in dairy heifers fed fresh oats with or without corn or barley grain. Journal of Dairy Science, v.83, p.746-755, 2000.

GONÇALVES, A.L.; LANNA, R.P.; RODRIGUES, M.T. et al. Efeito da relação volumoso:concentrado sobre a variação do pH ruminal em cabras leiteiras. In: REUNIÃO ANUAL DA SOCIEDADE BRASILEIRA DE ZOOTECNIA, 37., 2000, Viçosa, MG. Anais... Viçosa, MG: Sociedade Brasileira de Zootecnia, 2000. CD ROOM.

HARMON, D.L; RICHARDS, C.J. Considerations for gastrointestinal cannulations in ruminants. Journal of Animal Science, v.75, p.2248-2255, 2000.

HERRERA-SALDANA， R.E.; ALARCON-GOMEZ, R.; TORABI, M. et al. Influence of synchronizing protein and starch degradation in the rumen on nutrient utilization and microbial protein synthesis. Journal of Dairy Science, v.73, p.142-148, 1990a.

HERRERA-SALDANA, R.E.; HUBER, J.T.; POORE, M.H. Dry matter, crude protein, and starch degradability of five cereal grains. Journal of Dairy Science, v.73, p.2386-2393, 1990b.

HOF, G.; VERVOORN, M. D.; LENAERS, P.J. et al. Milk urea nitrogen as a tool to monitor the protein nutrition of dairy cows. Journal of Dairy Science, v.80, p.3333-3340, 1997.

HUNTINGTON, G.B.; GIVENS, D.I. The in situ technique for studying the rumen degradation of feeds: A review of the procedure. Nutrition Abstract and Reviews (Series B), v.65, p.63-93, 1995.

HUNTINGTON, G.B.; GIVENS, D. I. Studies on in situ degradation of feeds in the rumen: Effect of species, bag mobility and incubation sequence on dry matter disappearance. Animal Feed Science and Technology, v.64, p.227-241, 1997.

KHORASANI, G.R.; BOER, G.; ROBINSON, B. et al. Influence of dietary protein and starch on producttion and metabolic responses of dairy cows. Journal of Dairy Science, v.77, n.3, p.813-824, 1994.

LYKOS, T.; VARGA, G.A. Varying degradation rates of total nonstructural carbohydrates: effects on nutrient uptake and utilization by the mammary gland in high producing Holstein cows. Journal of Dairy Science, v.80, p.3356-3367, 1997.

MEHREZ, A.Z.; ØRSKOV, E.R. A study of the artificial fiber bag tecnique for determimmining the digestibility of feeds in the rumen. Journal of Agriculture Science, v.88, n.1, p.6450-6550, 1977.

NATIONAL RESEARCH COUNCIL - NRC. Nutrient requeriment of beef cattle. 7.ed. Washington, D.C.: National Academic Press, 1996. 242p. 
NOCEK, J.E.; TAMMINGA, S. Site of digestion of starch in the gastrointestinal tract of dairy cows and its effect on milk yield and composition. Journal of Dairy Science, v.74, p.3598-3629, 1991.

ORSKOV, F.N.; McDONALD, I. The estimation of protein degradability in the rumen from incubation measurements weighted according to rate of passage. Journal of Agriculture Science, v.92, p.499-510, 1979.

OVERTON, T.R.; CAMERON, M.R.; ELLIOTT, J.H. et al. Ruminal fermentation and passage of nutrients to the duodenum of lactating cows fed mixtures of corn and barley. Journal of Dairy Science, v.78, n.9, p.1981-1991, 1995.

PHILIPPEAU, C.; MARTIN, C.; MICHALET-DOREAU, B. Influence of grain source on ruminal characteristics and rate, site, and extent of digestion in beef steers. Journal of Animal Science, v.77, n.6, p.1587-1596, 1999.

RODRIGUES, L.A.; STALLINGS, C.C.; HERBEIN, J.H. et al. Diurnal variation in milk and plasma urea nitrogen in Holstein and Jersey cows in response to degradable dietary and added fat. Journal of Dairy Science, v.80, p.3368-3376, 1997.

SCHEPERS, A.J.; MEIJER, R.G. . Evaluation of the utilization of dietary nitrogen by dairy cows based on urea concentration in milk. Journal of Dairy Science, v.81, p.579-584, 1998.

SCHIMIDELY, P.; ARCHIMÈDE, H., BAS, P. et al. Effects of the synchronization of the rate of carbohydrates and nitrogen release of the concentrate on rumen fermentation, plasma metabolites and insulin, in the dry pregnant goat. Animal Feed Science and Technology, v.63, p.163-178, 1996.
SIMAS. J.M.C.; PIRES, A.V.; RIBEIRO, C.V.M. et al. Efeito de fontes de amido sobre parâmetros sangüíneos e ruminais de vacas Holandesas. In: REUNIÃO ANUAL DA SOCIEDADE BRASILEIRA DE ZOOTECNIA, 37., 2000, Viçosa, MG. Anais... Viçosa, MG: Sociedade Brasileira de Zootecnia, 2000. CD ROOM.

SISTEMA para ANÁLISE ESTATÍSTICA e GENÉTICA (SAEG). Viçosa: Universidade Estadual de Viçosa. Central de Processamento de Dados, 1983. 68p.

TALKE, H.; SCHUBERT, G. E. Enzymatische harnstoffbestimmung in blut und serum im optischen test nach warburg. Klinical Wochenschr, v.43, p. 174-175, 1965.

Van SOEST, P.J. Nutritional ecology of the ruminant. 2.ed. London: Cornell University, 1994. 476p.

YANG, W.Z.; BEAUCHEMIN, K.A.; KOENING, K.M. et al. Comparison of hull-less barley, barley or corn for lactating cows: Effects on extent of digestion and milk production. Journal of Dairy Science, v.80, n.2475-2486. 1997.
Recebido em: 24/05/01

Aceito em: 13/05/02 